\title{
EXPLORING UNDERLYING FACTORS INFLUENCING DAILY USAGE OF FACEBOOK FOR UNDERGRADUATE COLLEGE STUDENTS: A RESEARCH MODEL
}

\author{
Sushma Mishra, Robert Morris University, mishra@rmu.edu \\ Peter J. Draus, Robert Morris University,draus@rmu.edu \\ Gregory J. Leone, Robert Morris University, leone@rmu.edu \\ Donald J. Caputo, Robert Morris University, caputo@rmu.edu
}

\begin{abstract}
This study presents a research model which examines the factors influencing the frequency of Facebook usage in undergraduate students in a north eastern university in United States of America. The survey explores factors such as religion/ethnicity, academic major, access device, and employment status and its impact of frequency of usage of social networking sites. One hundred and twenty six responses were obtained and ANOVA was performed on the data. The results are discussed and future research directions presented. Conclusions were statistically derived, resulting in the retention of three null hypotheses, and the rejection of the one null hypothesis. .
\end{abstract}

Keywords: Facebook, academic performance, undergraduate student, access device, academic major, employment status, ANOVA,

\section{INTRODUCTION}

Social networking has rapidly evolved into a form of online communication that is deeply rooted into the very fabric of the personal relationships of college students. Current technological innovations and mobile devices now permit every student to maintain constantly moving social venues. Consequently, there have been striking changes in the ways and means used by today's youth to communicate socially. The rise in the continued use of social networking sites (SNS) such as Facebook, Twitter, LinkedIn, to name a few, has dramatically changed the landscape of socialization in today's world. SNS usage is getting widely accepted in society with recent data showing a high penetration rate among users [14]. The reach and penetration of Facebook in current use today is very strong. With over 500 million users, Facebook is now used by 1 in every 13 people on earth, with over 250 million of them (over $50 \%$ ) who $\log$ in every day [3]. The majority of the users are between 18-34 years old, and $48 \%$ of these users check Facebook when they wake up. The core 18-24 year old segment is now growing the fastest at $74 \%$ each year. Almost $72 \%$ of all US internet users are now on Facebook, while $70 \%$ of the entire user base is located outside of the United States [3]. This trend also suggests that one type of social media will not replace another but, rather, become integrated into a bundle of media use that includes online and offline forms of communication [1]. It can be inferred that different forms of social media has its own biases in terms of the kinds of communication it encourages and the rewards it provides for its users.

Today's young adult increasingly chooses the Internet as the dominant socializing tool. Adolescents and young adults are the heaviest computer and Internet users, primarily using it for completing school assignments (46\%), email and/or instant messaging (36\%), and playing computer games (38\%) [2]. Self-reported high usage of SNS, especially Facebook, raises concerns about this media's impact on the college life of students. However, despite this growth in older age groups, FB remains primarily a college-age and emerging adult phenomenon [10]. The high usage of Facebook is evident in the extensive activity documented by Facebook in the form of photo and video uploads, content and web link posts and events created. There is a need to conduct research examining the impact of Facebook on college life and academics. Students spend huge amounts of time on Facebook and it makes intuitive sense to determine how this impacts their academic performance [10].

This study uses Facebook as a specific SNS example to understand the relationships between SNS usage frequency and a student's academic major, religion/ethnicity, type of access media and employment status. There are several 


\section{Issues in Information Systems}

Volume 13, Issue 1, pp. 350-360, 2012

benefits of understanding student SNS usage behavior for universities. In order to integrate today's students with their university life or be able to communicate with them in a way which is more compatible with the students preferred way to communicate, it is evident that administrators of universities understand several aspects of student life and its interrelationship with usage of such omnipresent SNS.

The remaining portion of this paper is organized as follows. The next section presents a review of relevant literature in the area of Facebook usage. Following the literature review, the research model is presented. The relationship between dependent and independent variables are hypothesized. After introducing the model, data collection and analysis is presented. The results from the analysis are discussed. This section is followed by a discussion of results. This section also articulates the contributions of this study and notes the limitations as well. The final section presents the conclusion of the study with follow-up recommendations.

\section{LITERTURE REVIEW}

Facebook is an SNS developed in 2004 by former Harvard undergraduate student Mark Zuckerberg. This particular SNS allows the users to add friends, send messages, and update personal profiles in order to notify friends and peers about themselves. The company is also allowing users to form and join virtual groups, develop applications, host content, and learn about each other's' interests, hobbies, and relationship statuses through users' online profiles [18].

In a study by Ellison, Steinfield, and Lampe (2007) it was reported that found that $94 \%$ of undergraduate students at this particular University were Facebook users who spent approximately 10 to 30 minutes on the site per day and who had between 150 and 200 friends on average listed on their profile. It is also suggested by various studies in SNS usage behavior that Facebook is used and adopted primarily to maintain contact with offline connections rather than to develop new relationships [16]. In a study of 2,000 students, Lampe et al. (2006) found that Facebook is used by students for purposes related to "social searching" - that is, to learn more about someone they know offline, rather than for "social browsing"- the use of Facebook to develop new connections. Students reported using Facebook to "keep in touch with an old friend or someone I knew from high school" [16]. In a similar study by Ellison et al. (2007), similar results were found suggesting that students use Facebook for both maintaining preexisting close relationships (bonding social capital) and keeping in touch with high school acquaintances and classmates (maintaining social capital). In terms of binding with old friends, this study suggests that Facebook provides a low-maintenance way for users to keep involved in lives of their friends. In the context of maintaining social capital, Ellison et al. suggest that Facebook allows users to maintain a connection to "weak ties," for example, high school acquaintances who may be able to provide valuable new information and resources. In summary, these studies indicate that Facebook serves a sociability function-one that enables users to maintain relationships with offline connections both near and far.

Research on impact of technology usage on academic achievement suggests a correlation between the two. Positive and negative effects of technology on achievement have been documented. Lei and Zhao (2005) researched the specifics of access, acknowledging that quantity is not as important as quality when it comes to technology use and student achievement. Specifically, when the quality of technology use is not closely monitored or ensured, computer use may do more harm than good to student achievement in school. Researchers have found that there is a strong correlation between Internet use and academic performance [12]. Especially noted, high school students have reported that not being able to control their Internet usage has impacted their academic work. Kolek and Saunders (2008) found no correlation between Facebook use and GPA in a sample of students from a public Northeast research university. Similarly, an exploratory survey study reported a negative relationship between Facebook use and academic achievement as measured by self-reported GPA and hours spent studying per week [9]. On the contrary, a more recent study by Kirschner and Karpinski (2010) concludes that there is a significant negative relationship between FB use and academic performance. FB users reported lower mean GPAs and reported spending fewer hours per week studying on average than FB nonusers. The authors caution here that while FB use is something that students do concurrently with studying or other activities that may enhance their academic performance, the negative relationship found might be an indication of a deleterious effect of trying to implement these two processes at the same time [10].

There are several motivations that have been noted in research literature in this area. In research, to study motivations for joining Facebook, a distinction is made between gratifications obtained and gratifications sought 


\section{Issues in Information Systems}

Volume 13, Issue 1, pp. 350-360, 2012

[18]. Gratifications obtained refer to those gratifications that audience members actually experience through the use of a particular medium. By contrast, gratifications sought (also often referred to as "needs" or "motives") refer to those gratifications that audience members expect to obtain from a medium before they have actually come into contact with it [18]. The key premise to study gratifications obtained by users is that obtained gratifications may differ from those sought and the resulting gap can predict the level of satisfaction/dissatisfaction that individuals experience from the usage of a particular medium [17]. Understanding the gap between these two types of gratifications is important for analyzing how different audience members use various kinds of media, and the expectations that they bring to their media habits.

A Study conducted at Ohio State University in 2008 about Facebook usage characteristics in undergraduate and graduate students suggests that students who have active employment status in a paid job are less likely to use Facebook than full time students with no jobs [19]. The same study also suggested that science, technology, engineering, math and business majors were more likely to use Facebook than students majoring in the humanities and social sciences [19]. The study concluded that non-Facebook users spent more (approximately twice) time studying during the week than Facebook users. It suggests that students are spending too much time socializing on Facebook which is distracting them from their studies and hurting academic performance. A review of the available research suggests that there is little research available in understanding the relationship between student's academic characteristics and the frequency of usage of SNS. This study addresses this gap.

\section{Research Model}

In this research, we are studying what impacts the Facebook usage of students. We have one dependent variable, frequency of Facebook usage, and five independent variables. Based on the conceptual relationship of the variables, their effect is hypothesized.

\section{Dependent Variable}

Facebook usage frequency could be defined as the "number of hours/day a user is a using the services of the particular site". The tremendous growth in Facebook's number of users and frequency of use and also based on anecdotal evidences, it is expected that this is an ever growing trend. We have captured this variable in our survey by directly asking the students about the approximate number of hours of usage per day. It is self-reported data.

\section{Independent Variables}

Academic Major: Students across the board, irrespective of their majors or class standing, have suggested that they are avid users of Facebook. Based on our literature review in this area, there is little reason to believe that the choice of the major of a student would impact their Facebook usage. Based on this intuitive reasoning, we hypothesize:

H1: There is no difference in SNS usage due to academic interest as defined by students' major

Religion/ethnicity: Facebook revolution is a global phenomenon with a user base across several countries. People of various religion and ethnicity are frequently using this site. Based on the anecdotal reports and conceptual reasoning, we hypothesize that:

H2: Religion and ethnicity have no bearing on SN usage

Access Device: There are several types of media devices available to users to access Facebook. Students use laptops, smart phone and tablets for Facebook usage. Considering students do not feel restricted by the choice of media for accessing Facebook, we hypothesize that:

H3: There is no difference in usage behavior of students based on the type of media they use for access (Tablet, smartphone or laptop)

Employment Status: Students need to have more free time to access Facebook. It makes more intuitive sense to assume that students who have are active employment (fulltime/part-time) will have less free time to access Facebook than the students who do not have any current employment and are full time students. Hence, our next hypothesis: 


\section{Issues in Information Systems}

Volume 13, Issue 1, pp. 350-360, 2012

H4: Students who work full time/part time would spend less time on SNS than ones who are full time students with no active employment

Based on the above hypothesis, we propose the following model (figure 1):

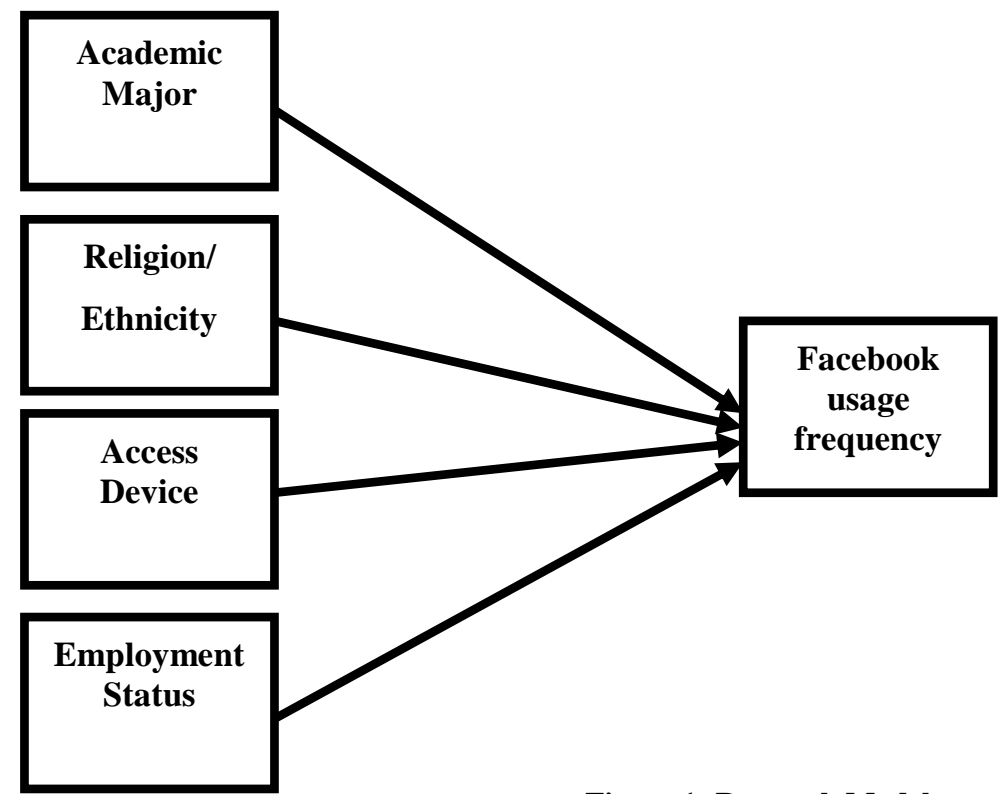

Figure 1: Research Model

\section{DATA COLLECTION AND ANALYSIS}

\section{Demographics}

A survey was administered in a north eastern small private school. The survey consisting of 24 questions was administered in an introductory INFS course that is part of the university core curriculum. The survey gathered basic demographic information including participation in university clubs and sports teams. It also gather information of the students current work status and their social media experiences and expectations. 129 students in 7 course sections completed the survey. The age ranged from 17 to 29 with a mean of 19.2. All but one of the subjects was a full time student. The sample consisted of $60 \%$ men and $40 \%$ women, which closely matched the university's overall gender distribution of 56\% 44\%. 126 out of the 129 used Facebook as their primary social media site. The years of Facebook usage ranged from less than 1 year up to 11 years with a mean of mean 3.7 years.

Students reported using Facebook from 0-24 hours a day with a mean 4.55 and a median of 2 hours. Hours worked ranged from 0-40 with a mean of 11.26 hours/week. The breakdown of Full time to part time is shown below: $4.3 \%$ worked full time, $42 \%$ worked part time and $49 \%$ didn't work at all. The subjects reported belonging to 10 different religions which were grouped into 4 categories for analysis in the study. University club participation ranged from 0-8 with a mean of 1 . While only 26 subjects reported playing one sport, only 2 reported participated in two university sports teams. A basic social participation index was created from the number of clubs and sports students participated in. An advanced social index included the amount of work involved.

\section{Results}

The dependent variable for the research questions was the number of hours students were on Facebook each day. Looking at the Histogram (figure 2) the data did not appear to be normalized. 


\section{Issues in Information Systems}

Volume 13, Issue 1, pp. 350-360, 2012

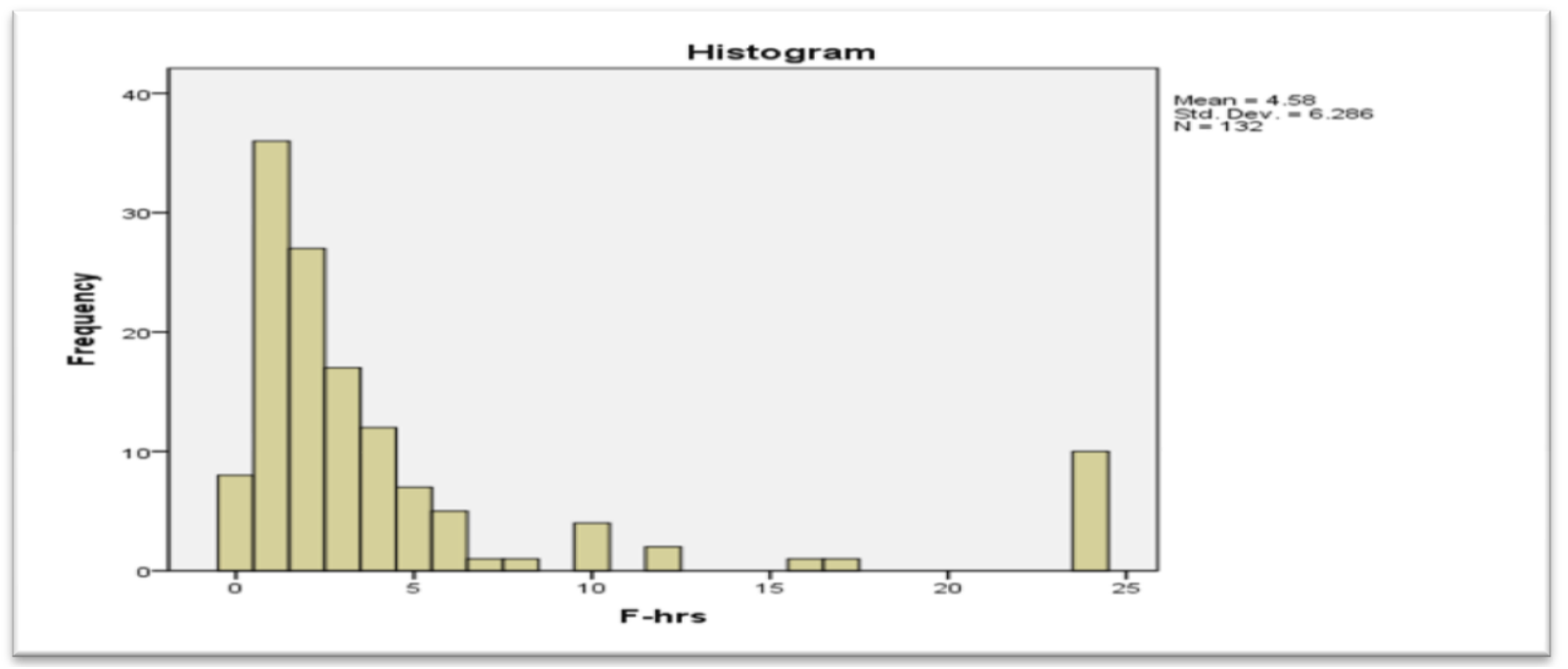

Figure 2: Histogram of data

Both the Kolmogorov-Smirnov and Shapiro-Wilk tests of normalcy (Table 1) were significant, meaning the data were not normal.

Table 1: Tests of Normality

\begin{tabular}{|l|l|l|l|l|l|l|}
\hline & Kolmogorov-Smirnov & & & Shapiro-Wilk & & \\
\hline & Statistic & Df & Sig. & Statistic & df & Sig. \\
\hline F-hrs & 294 & 132 & .000 & .612 & 132 & .000 \\
\hline a. Lilliefors Significance Correction & & & & & & \\
\hline
\end{tabular}

While the outliers of 24/hours a day, by definition, can't be true, they do represent high usage individuals. Instead of relying on the robustness of the ANOVA the Independent Samples Means test was substituted to test for differences between groups.

\section{Access Device Table 2: Report of F-Hours based on access device}

Student's prime device for connecting to Facebook was collected. As expected there was a significant difference in the amount of time spent using Facebook between the groups with the subjects reporting using a smartphone for access having the highest group mean usage of 6.77 hours/day (Table 2). Not surprisingly 8 of the 10 subjects reporting using Facebook 24 hours a day reporting a smartphone as their prime access device.

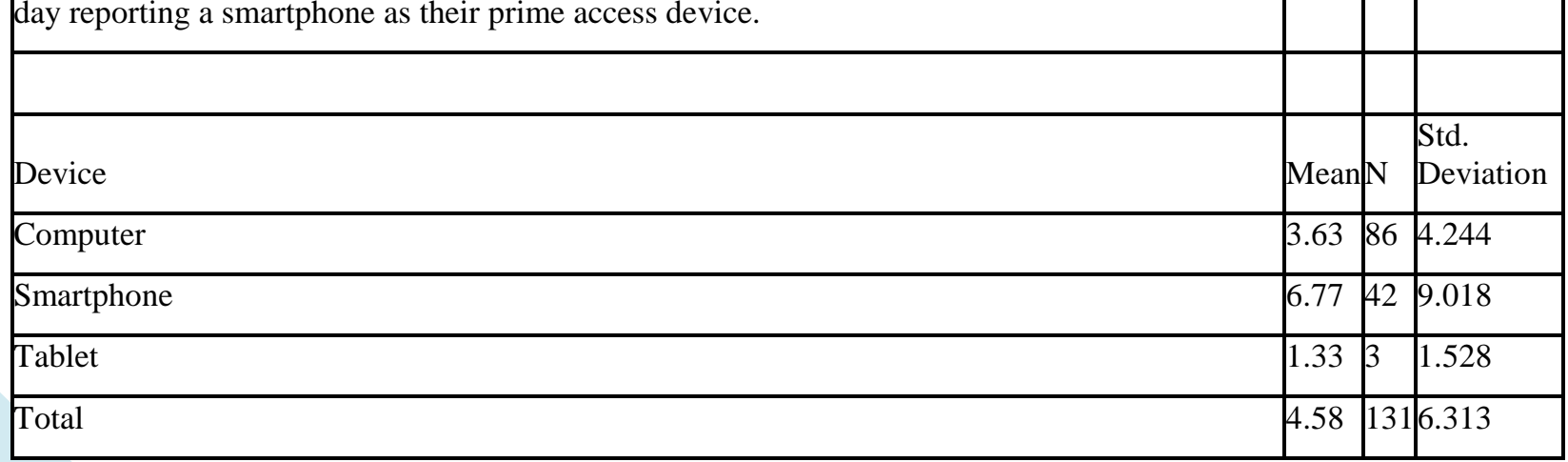




\section{Issues in Information Systems}

Volume 13, Issue 1, pp. 350-360, 2012

Our hypothesis for the device type of access was accepted. There is no difference in the usage frequency of Facebook due to device type (Figure 3).

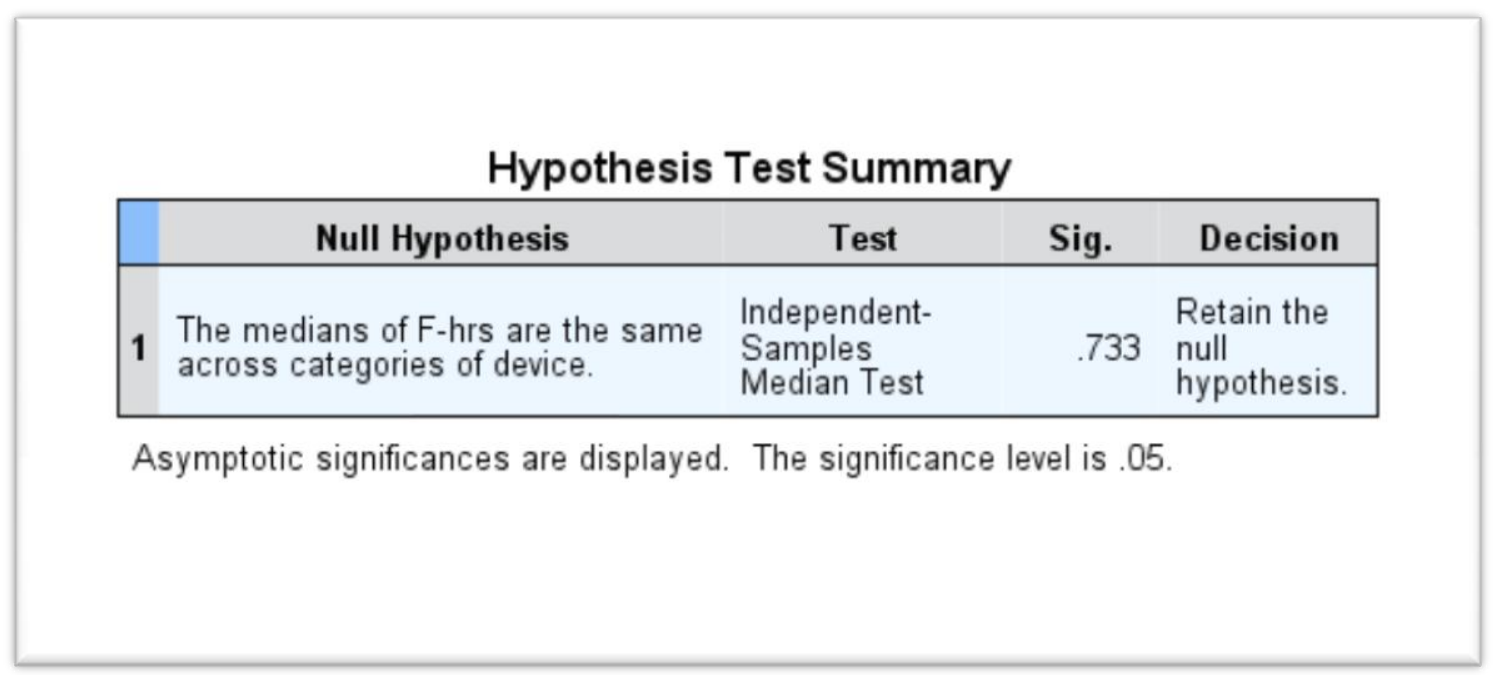

Figure 3: Test summary for Hypothesis 1

\section{Employment Status:}

Table 3: Correlation between Facebook usage and hours worked

\begin{tabular}{|c|c|c|c|c|}
\hline \multicolumn{5}{|c|}{$\begin{array}{l}\text { According to our data and analysis, there was no significant correlation } \\
\text { between hours a subject worked and the number of hours on Facebook } \\
\text { (Table 3). }\end{array}$} \\
\hline & & & $\begin{array}{l}\text { F- } \\
\text { hrs }\end{array}$ & H_wkd \\
\hline \multirow[t]{6}{*}{ Spearman's rho } & F-hrs & $\begin{array}{l}\text { Correlation } \\
\text { Coefficient }\end{array}$ & 1.000 & .043 \\
\hline & & Sig. (2-tailed) & & .673 \\
\hline & & $\mathbf{N}$ & 132 & 100 \\
\hline & H_wkd & $\begin{array}{l}\text { Correlation } \\
\text { Coefficient }\end{array}$ & .043 & 1.000 \\
\hline & & Sig. (2-tailed) & .673 & \\
\hline & & $\mathbf{N}$ & 100 & 102 \\
\hline
\end{tabular}

We did not see any differences in the group as well. Our hypothesis about differences in Facebook usage frequency due to employment status of students was rejected (Figure 4). 


\section{Issues in Information Systems \\ Volume 13, Issue 1, pp. 350-360, 2012}

Hypothesis Test Summary

\begin{tabular}{|c|c|c|c|c|}
\hline & Null Hypothesis & Test & Sig. & Decision \\
\hline 1 & $\begin{array}{l}\text { The medians of F-hrs are the same } \\
\text { across categories of Work_status. }\end{array}$ & $\begin{array}{l}\text { Independent- } \\
\text { Samples } \\
\text { Median Test }\end{array}$ & .723 & $\begin{array}{l}\text { Retain the } \\
\text { null } \\
\text { hypothesis. }\end{array}$ \\
\hline
\end{tabular}

Asymptotic significances are displayed. The significance level is .05.

Figure 4: Test summary for hypothesis 2

\section{Religion/ethnicity:}

Based on our data, there was no difference between the Facebook hours for student's ethnicity (Figure 5).

Hypothesis Test Summary

\begin{tabular}{|lllcl|}
\hline \multicolumn{2}{|c}{ Null Hypothesis } & \multicolumn{1}{c|}{ Test } & Sig. & Decision \\
\hline 1 & $\begin{array}{l}\text { The medians of F-hrs are the same } \\
\text { across categories of Ethnicity. }\end{array}$ & $\begin{array}{l}\text { Independent- } \\
\text { Samples } \\
\text { Median Test }\end{array}$ & $.103 \begin{array}{l}\text { Retain the } \\
\text { null } \\
\text { hypothesis. }\end{array}$ \\
\hline
\end{tabular}

Asymptotic significances are displayed. The significance level is .05 .

Figure 5: Test summary for hypothesis 3

\section{Academic Major}

We hypothesized that there is no difference in SNS usage frequency due to academic interest as defined by students' major. Our data suggests that there is a significant difference and rejects the hypothesis. 


\section{Issues in Information Systems}

Volume 13, Issue 1, pp. 350-360, 2012

Hypothesis Test Summary

\section{Null Hypothesis}

The medians of F-hrs are the same

1 across categories of Major_combined.
Test

Independent-

Samples

Median Test
Sig.

.022

null

Reject the

hypothesis.

Asymptotic significances are displayed. The significance level is 05 .

Figure 6: Test summary for hypothesis 4

Table 4: Report on F-Hours for different academic majors

Report of usage based on academic major (Table 4 below) suggests that students with social sciences major use Facebook more on a daily basis than students with Business and Sciences Majors.

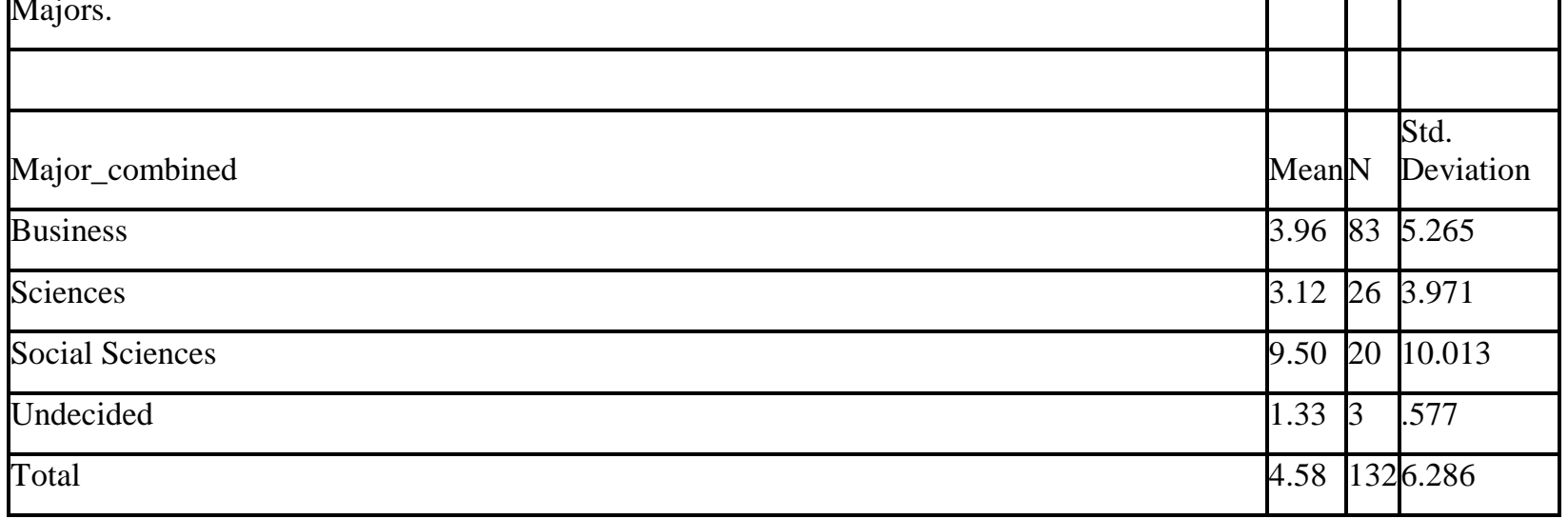

In summary of our results is presented below in the table 5:

Table 5: Summary of hypothesis testing results

\begin{tabular}{|l|l|}
\hline Hypotheses & Status \\
\hline H1: There is no difference in SNS usage due to academic interest as defined by students' major & Rejected \\
\hline H2: Religion and ethnicity have no bearing on SN usage & Accepted \\
\hline
\end{tabular}

H3: There is no difference in usage behavior of students based on the type of media they use for access Accepted (Tablet, smartphone or laptop)

H4: Students who work full time/part time would spend less time on SNS than ones who are full time Rejected students with no active employment 


\section{Issues in Information Systems}

Volume 13, Issue 1, pp. 350-360, 2012

\section{DISCUSSIONS}

A surprising result from the survey of social networking usage indicated a significant difference among academic majors. Robert Morris University offered fifty undergraduate majors during the term the students were surveyed. For this study the various majors were generalized into three main categories. These categories were business, social sciences, and science.

Students in the science majors were significantly greater users of social networking than the other disciplines. The specific majors that were included in the science group were mathematics, engineering, environmental science and actuarial science. Students in these majors enter the university with the highest board scores and highest high school grade point average. Given the rigors of the science majors and the academic records of these students upon entry into the university they are considered the best and brightest as a group of students. The science students used the social networking sites an average of 9.50 hours per day compared to the business student usage of 3.96 hours per day and the social science majors using 3.50 hours per day. There is very little research in this aspect of Facebook.

Our second hypothesis was accepted suggesting that religion/ethnicity has little role to play in a student's Facebook usage frequency. This relationship was proposed based on the widespread increasing demand of Facebook students in young people across the globe. Hypothesis H3 suggests that students would use Facebook as much as they want without being restricted by access devices they use to get connected to the service. Considering the widespread usage of smartphones and tablets by users along with even wider use of laptops for academic purposes, this result is consistent with our expectations. Students today have access to various access devices and these choices are more liberating to the students than restricting in the terms of Facebook usage, providing better opportunities to get connected as much as they want, as long as they want, and wherever they want it.

Finally, the last hypothesis about the employment status of students and Facebook usage frequency was rejected. We proposed this relationship with the consideration that employers are increasingly becoming restrictive about SNS usage at work and discourage employees to use such sites. Many employers would block such SNS sites in their internal network. There could be several possible reasons why this hypothesis did not hold up. Undergraduate students typically have employment at small organizations which do not have a mature anti-SNS-use policy. Students could use their personal devices such as smart phones or tablets to access their accounts even while at work. It is plausible that the sample that we had for this survey was not representative of the real life job environment.

\section{CONTRIBUTIONS AND LIMITATIONS}

This study contributes in several ways to the research literature of SNS. First, there is little research available which can establish a relationship between academic parameters and SNS usage frequency for students. This study adds to the body of knowledge by exploring this academic aspect of Facebook usage frequency. Second, there are little empirical evidences to establish relationship between SNS usage and academic performance. Several studies can stem from this work exploring other dimensions of academic parameters and SNS usage. Third, this research provides an insight into today's undergraduate students and their affinity towards SNS such as Facebook. University administrators can draw lessons from this study reevaluating the strategies to engage students more in academic pursuits. Employers can draw lessons from this study in terms of usage of such sites at the work place and associated productivity losses.

There are certain limitations to this study. One important drawback is that we have examined just one community of students in this study. The unique representation of RMU community in this study might not make the results generalizable across other communities. For example, the sample characteristics in terms of religion and ethnicity of students could differ based on a school's location and type (private vs. public). Finally, respondents may have misreported behavioral or demographic information, as we used self-reported rather than direct measures of Facebook use and other variables. 


\section{Issues in Information Systems}

Volume 13, Issue 1, pp. 350-360, 2012

\section{CONCLUSION}

This study explored the impact of certain academic criteria on the usage pattern of Facebook in undergraduate students. A research model was developed and relationships between four independent variables described as access media, religion/ethnicity, academic major and employment status and one dependent variable, Facebook usage frequency was hypothesized. A survey was developed and conducted in introductory information systems courses at RMU. Results were analyzed using SPSS.

Our empirical findings contradict some of the anecdotal evidences represented by the popular press. Our findings suggest that student's Facebook usage frequency is dependent on their academic major as well as the access device that they use to get connected to the site. We also found that Facebook usage frequency in undergraduate students does not depend on their religious/ ethnicity status which is in agreement with the widespread popularity of this site across the globe. Also, we reported that Facebook usage intensity is independent of the student's employment status. Today's student uses Facebook even at work either through their work machine or through their personal portable device. There is little research in the SNS domain exploring the relationships between students Facebook usage frequency and other academic indicators. Limitations are listed and contributions are established. This stream of research in Facebook that analyzes the academic life of students based on their Facebook usage looks like a promising avenue for several future research opportunities.

\section{REFERENCES}

1. Baym, N. K., Zhang, Y. B., \& Lin, M.-C. (2004). Social interactions across media: Interpersonal communication on the internet,telephone and face-to-face. New Media \& Society, 6, 299-318.

2. DeBell, M., \& Chapman, C. (2006). Computer and Internet use by students in 2003 (NCES 2006-065). US Department of Education. Washington, DC: National Center for Education Statistics

3. Digitalbuzzblog.com, (2011) Facebook Statistics, Stats and Facts for 2011, Retrieved on 02/22/12 http://www.digitalbuzzblog.com/facebook-statistics-stats-facts-2011/

4. Ellison, N. B., Steinfield, C., \& Lampe, C. (2007). The benefits of Facebook "friends": Social capital and college students' use ofonline social network sites. Journal of Computer Mediated Communication,12(4). Retrieved from http://jcmc.indiana.edu/vol12/issue4/ellison.html

5. Felt, A. and D. Evans (2008). "Privacy protection for social networking APIs." 2008 Web 2.0 Security and Privacy(W2SP'08).

6. Hempel, J. and P. Lehman (2005). "The MySpace Generation." Business Week 3963: 86.

7. Hogben, G. (2007). "Security issues and recommendations for online social networks." Position Paper. ENISA, European Network and Information Security Agency.

8. Jones, H. and J. Soltren (2005). "Facebook: Threats to privacy." Project MAC: MIT Project on Mathematics and Computing.

9. Karpinski, A. C. \& Duberstein, A. (April 16, 2009). A description of Facebook use and academic performance among undergraduate and graduate students. In Poster presented at the meeting of the American Educational Research Association, SanDiego, CA.

10. Kirschner, P. and Karpinski, A. (2010) Facebook and academic performance, Computers in Human Behavior, 26 (2010), p.1237-1245

11. Kolek, E. A., \& Saunders, D. (2008). Online disclosure: An empirical examination of undergraduate Facebook profiles. NASPA Journal, 45(1), 1-25

12. Kubey, R. W., Lavin, M. J., \& Barrows, J. R. (2001). Internet use and collegiate academic performance decrements: Early findings. Journal of Communication, 51, 366-382.

13. Krasnova, H., S. Spiekermann, et al. (2010). "Online social networks: why we disclose." Journal of Information Technology25(2): 109-125.

14. Lenhart, A. (2009). Adults and social network websites. Washington,DC: Pew Internet and American Life Project. Retrieved from http://www.pewinternet.org/Reports/2009/Adults-and-Social-Network-Websites.aspx

15. Lei, J., \& Zhao, Y. (2005). Technology uses and student achievement: A longitudinal study. Computers \& Education, 49, 284-296. 


\section{Issues in Information Systems}

Volume 13, Issue 1, pp. 350-360, 2012

16. Lampe, C., Ellison, N., Steinfield, C. (2006). A Face(book) in the crowd: Social searching vs. social browsing. Proceedings of the 2006 20th Anniversary Conference on Computer Supported Cooperative Work (pp. 167170). New York: ACM Press

17. Palmgreen, P., Wenner, L. A., \& Rayburn, J. D. (1980). Relations between gratifications sought and obtained: A study of television news. Communication Research, 7, 161-192.

18. Quan-Haase, A and Young, A. (2010) Uses and Gratifications of Social Media: A Comparison of Facebook and Instant Messaging, Bulletin of Science, Technology \& Society, 30(5) 350-361

19. Stein, R. (2009) Does Facebook Lead to Bad Grades?, Washington Post, Retrieved on 02/25/12

20. http://voices.washingtonpost.com/checkup/2009/04/does_facebook_lead to bad_grad.html 